Purdue University

Purdue e-Pubs

CTRC Research Publications

Cooling Technologies Research Center

2011

\title{
Transport in Passive, High Thermal Conductivity Heat Spreaders
}

R. Ranjan

S V. Garimella

Purdue University, sureshg@purdue.edu

J.Y. Murthy

Follow this and additional works at: http://docs.lib.purdue.edu/coolingpubs

Ranjan, R.; Garimella, S V.; and Murthy, J. Y., "Transport in Passive, High Thermal Conductivity Heat Spreaders" (2011). CTRC Research Publications. Paper 234.

http://docs.lib.purdue.edu/coolingpubs/234

This document has been made available through Purdue e-Pubs, a service of the Purdue University Libraries. Please contact epubs@purdue.edu for additional information. 


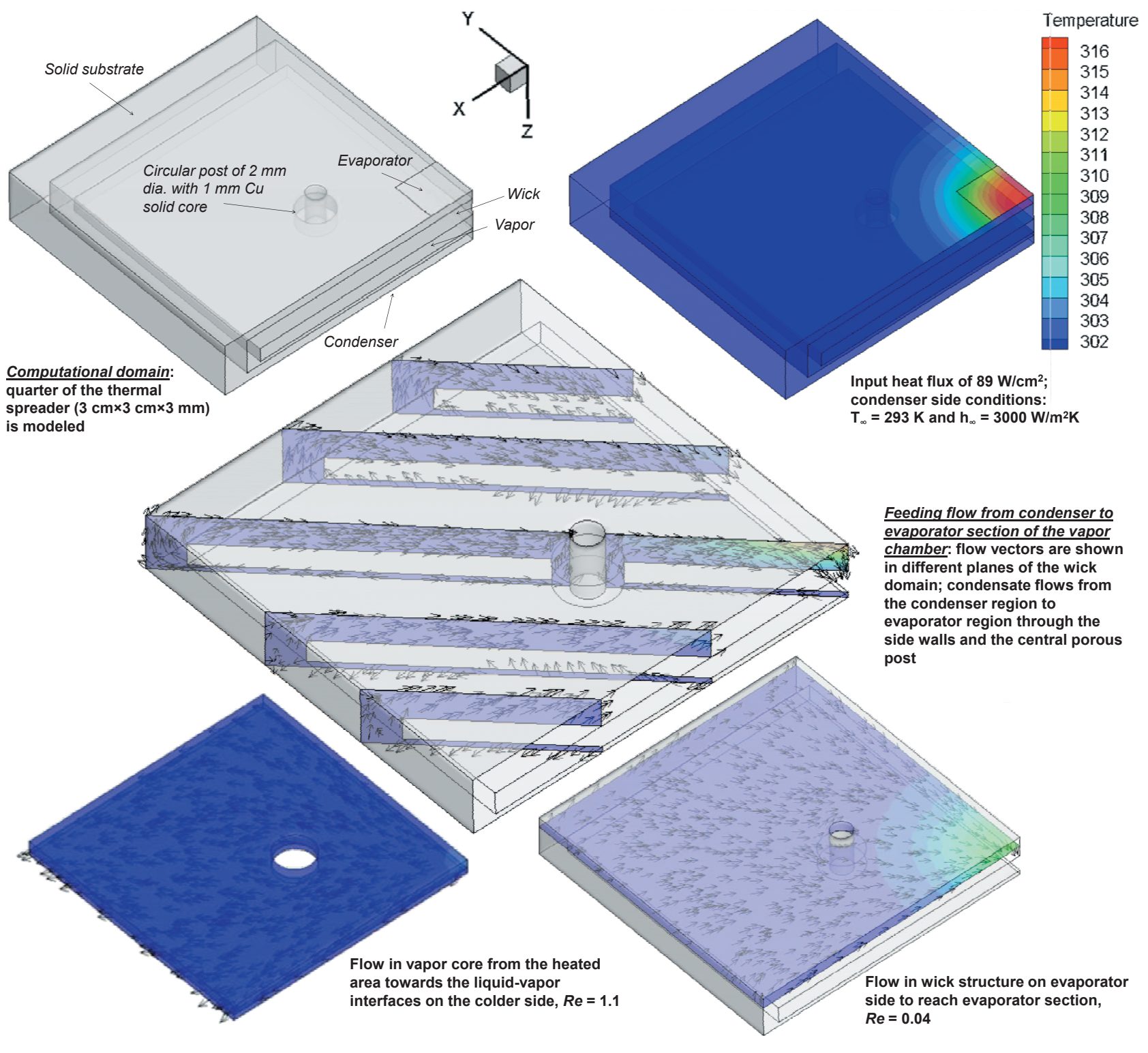

Transport in Passive, High Thermal Conductivity Heat Spreaders

Ram Ranjan, Suresh V. Garimella and Jayathi Y. Murthy

NSF Cooling Technologies Research Center

School of Mechanical Engineering, Purdue University, West Lafayette, Indiana 47907-2088 USA

A transient, three-dimensional model for thermal transport in heat pipes and vapor chambers is developed. The Navier-Stokes and energy equations are solved numerically. A porous medium formulation is used for the wick region. Phase change at the liquid-vapor interface is modeled using kinetic theory. The performance of a $3 \mathrm{~mm}$ thin vapor chamber with four circular porous posts inside the vapor core is predicted. Liquid flows from the condenser to the evaporator through two separate paths, viz., the side walls and the porous posts, which lead to a shorter path for liquid return, and decrease the liquid pressure drop. Optimal placement of the porous posts would help increase the capillary limit of the heat pipe. 